\title{
MEASURING HYDROGEN BY COLD-NEUTRON PROMPT-GAMMA ACTIVATION ANALYSIS
}

\author{
R. M. LINDSTROM, * R. L. PAUL, ${ }^{*}$ D. H. VINCENT, ${ }^{* *}$ R. R. GREENBERG* \\ *Inorganic Analytical Research Division, National Institute of Standards and Technology, \\ Gaithersburg, MD 20899 (USA) \\ **Department of Nuclear Engineering, The University of Michigan, Ann Arbor, MI 48109 (USA)
}

(Received January 4, 1994)

\begin{abstract}
By irradiating with cold neutrons and avoiding hydrogenous materials of construction, we have developed a PGAA instrument at the Cold Neutron Research Facility at NIST with hydrogen detection limits in the microgram range in many materials. Quantities of 5-10 $\mu \mathrm{g} \mathrm{H} / \mathrm{g}$ are presently measurable in graǹ-sized samples of silicon or quartz, and of order $0.01 \mathrm{wt} \%$ can be quantitatively measured in complex silicate rocks.
\end{abstract}

Hydrogen is well known to cause significant embrittlement in steels at levels of 10 $\mu \mathrm{g} / \mathrm{g}$, and affects the cracking strength of titanium alloys at a total concentration of $50 \mu \mathrm{g} / \mathrm{g}$ or less ${ }^{1}$. In semiconductors, hydrogen shows bulk electrical effects at $10 \mu \mathrm{g} / \mathrm{cm}^{3}$ or even lower ${ }^{2}$. There has long been a need for reliable $\mathrm{H}$ determination at low concentrations. The most common analytical procedures call for destructive high-temperature extraction, either by melting or oxidizing the matrix. The extracted $\mathrm{H}_{2}$ or $\mathrm{H}_{2} \mathrm{O}$ is separated from other gases and measured by gas chromatography or gravimetry. These methods are destructive, and not always accurate. They are used because they are rapid and inexpensive, and because no nondestructive, non-extractive method is available.

Neutron-capture prompt gamma-ray activation analysis (PGAA) has been used at the National Institute of Standards and Technology (NIST) and by several other laboratories for measurement of hydrogen concentrations in a variety of samples. The thermal neutron capture cross section is 0.333 barns, each capture giving a $2223.23 \mathrm{keV}$ gamma ray. The sechnique is wholly nondestructive, which is important when the analytical sample is to be used for subsequent experiments. It is also specific, which is vital for characterizing standard materials and for the calibration of other methods.

The University of Maryland has operated a PGAA system at the NIST Reactor since $1977^{3}, 4$. Because the neutron beam of this system contains about $2 \%$ epithermal neutrons, the radiation shielding around the apparatus must contain thermalizing material to slow these neutrons for efficient absorption. The beam tube, beam stop, and detector shield are accordingly surrounded by thick layers of lithium- and boron-loaded paraffin and polyester, containing more than $10 \mathrm{~kg}$ of hydrogen in all. As a consequence, the background spectrum is dominated by the 2223-keV hydrogen capture peak and its Compton distribution. The background count rate is equivalent to about $1 \mathrm{mg}$ of hydrogen. Nevertheless, the Maryland group has reported hydrogen concentrations as low as $200 \mu \mathrm{g} / \mathrm{g}$ by PGAA in concrete and other construction materials 5 and geochemical reference standards ${ }^{6}$.

\footnotetext{
*Contributions of the National Institute of Standards and Technology are not subject to copyright.
} 


\section{Experimental}

As several publications have pointed out in recent years 7,8 , the use of filtered or bent neutron guides in PGAA can remove all the epithermal and fast neutrons from the beam, and the resulting pure thermal neutrons can then be stopped in lightweight, hydrogen-free absorbers. Three such systems are now in operation for multielement chemical analysis: at KFA, Jülich, Germany ${ }^{8}$, at JAERI, Tokai, Japan ${ }^{9}$, and at NIST. At least four more, to our knowledge, are planned to become available in the near future.

The NIST system ${ }^{10,11}$, constructed as part of the Cold Neutron Research Facility $(\mathrm{CNRF})^{12}$, uses neutrons from a large $\mathrm{D}_{2} \mathrm{O}$ cold source located $41 \mathrm{~m}$ from the PGAA station. The sample is positioned $30 \mathrm{~mm}$ from an adjacent guide serving another instrument; in order to avoid a high background from the boron capture gamma ray, this guide section is made of boron-free glass (see the figure in ref. 11). The slabs of glass comprising the guide are held together with silicone rubber adhesive. An absorbing layer of ${ }^{6} \mathrm{Li}$ outside the guide stops the neutron leakage flux (of order $10^{3} \mathrm{n} / \mathrm{s}$ per square centimeter of guide surface) which results from beam divergence and from surface imperfections and misalignments of the guide sections. The absorber is a paint consisting of ${ }^{6} \mathrm{LiF}$ added to a commercial graphite suspension ( $6 \mathrm{~g}^{6} \mathrm{LiF} / \mathrm{g} \mathrm{C}$ ) intended for electron tube manufacture ${ }^{13}$. In addition to the graphite, the base lacquer, was found to contain $20 \mathrm{mg} \mathrm{H} / \mathrm{g} \mathrm{C}$ in the binder after air drying at room temperature. Transmission measurements showed that $15 \mathrm{mg}{ }^{6} \mathrm{Li} / \mathrm{cm}^{2}$ was sufficiently thick to remove $99 \%$ of the cold neutrons, in accord with calculations. This thickness of paint contains $0.3 \mathrm{mg} \mathrm{H} / \mathrm{cm}^{2}$. When coated on the guide, however, the paint was not as efficient an absorber as expected, the explanation for which is not clear. For this reason, and because of the residual hydrogen, this paint will eventually be replaced by ${ }^{6} \mathrm{Li}$ glass $^{14}$ or LiF ceramic 7 .

Specimens are generally packaged in heat-sealed $25-\mu \mathrm{m}$ Teflon FEP film*, which is suspended in the beam with FEP or PFA monofilament strings. The hydrogen background of an empty package is not measurably different from that with nothing in the beam. The hydrogen background in air at present averages $0.07 \pm 0.01 \mathrm{c} / \mathrm{s}$, which corresponds to $20 \mu \mathrm{g}$ $\mathrm{H}$. Since the calculated hydrogen content in the volume of the beam visible to the detector (about $6 \mathrm{~cm}^{3}$ ) is $8 \mu \mathrm{g}$ at $25^{\circ} \mathrm{C}$ and $50 \%$ relative humidity, at microgram levels the samples need to be irradiated in a dry atmosphere. Enclosing the beam path in a tent of FEP flooded with $\mathrm{He}$ reduces the background to below $10 \mu \mathrm{g}$. As discussed above, the neutron guide adjacent to the sample is a source of hydrogen background in the apparatus, and indeed the background is $5 \mu \mathrm{g}$ when the PGAA shutter is closed. The permanent passive shielding and sample support assembly now being designed will reduce the background substantially, and facilitate the establishment of a dry atmosphere.

\section{Results}

The PGAA system has been used for the analysis of hydrogen in a number of samples originating from NIST programs and from academic and industrial laboratories with whom NIST collaborates. We give below a series of examples to demonstrate the utility of the method.

\footnotetext{
* Certain commercial equipment, instruments, or materials are identified in this paper in order to specify the experimental procedures in adequate detail. This identification does not imply recommendation or endorsement by the authors or by the National Institute of Standards and Technology, nor does it imply that the materials or equipment identified are necessarily the best available for the purpose.
} 
Hydrogen was measured in 1-g specimens of hydrothermally grown single-crystal quartz, preliminary to a neutron scattering experiment. Fused quartz was used as a blank. The concentrations determined (Table 1) were found to be much lower than expected, so low that the planned scattering measurement was not possible.

Table 1: Concentration of Hydrogen in Quartz Samples

\begin{tabular}{ll}
\hline Sample & H content, $\mu \mathrm{g} / \mathrm{g}$ \\
\hline GC17 & $8 \pm 8$ \\
GC248 & $<8$ \\
TD4 & $6 \pm 6$ \\
TD7C & $<5$ \\
TD7D & $10 \pm 6$ \\
Blank $(2 \mathrm{~g})$ & $4 \pm 3$ \\
\hline
\end{tabular}

In another application, hydrogen was sought for in a $1.0-\mu \mathrm{m}$ phosphosilicate glass film deposited on a quarter of a $15-\mathrm{cm}$ silicon wafer $670 \mu \mathrm{m}$ thick. In this case the sample was larger than the $20 \mathrm{~mm}$ diameter of the beam, so the results were expressed on an area basis; the effective sample mass was about $1 \mathrm{mg}$. The hydrogen standard was a polyimide sheet $\left(23 \mu \mathrm{g} \mathrm{H} / \mathrm{cm}^{2}\right)$ the same shape as the sample, and the blank was an uncoated silicon wafer. The hydrogen signal was weak, but the sample showed a larger hydrogen signal than the blank. The net hydrogen content in this sample was $0.96 \pm 1.27 \mu \mathrm{g} / \mathrm{cm}^{2}$, which corresponds to $6 \pm 9 \mathrm{wt} \%$ of water in the film. This measurement also reassured experimenters on another instrument in the CNRF that a similar uncoated semiconductorgrade silicon wafer used as a neutron beam window was not likely to contain so much hydrogen that scattering would lead to detectable loss of neutron flux.

In cooperation with other analysts who were searching for a systematic error in the assay of noble metais, we determined that the hydrogen content of a 20 -mg specimen of precipitated Rh metal was less than $0.1 \mathrm{wt} . \%$ (95\% confidence limit), and therefore occluded hydrogen could not be the source of the analytical error.

Hydrogen was measured in NIST Standard Reference Material 354 Titanium. In a 2.6-hour irradiation of a $234-\mathrm{mg}$ sample we measured $235 \pm 30 \mu \mathrm{g} / \mathrm{g}$; the certified concentration is $215 \pm 6$. The capture spectrum of $\mathrm{Tl}$ is complex in the region around the $2223 \mathrm{keV} \mathrm{H}$ capture line (peaks at 2201, 2205, and $2240 \mathrm{keV}$ ) so that a careful choice of integration region is necessary. For the same reason, hydrogen is also difficult to measure in iron and steel. A nearby iron peak at $2209 \mathrm{keV}$ and the Compton continuum from the highenergy capture gamma rays set the detection limit to $30 \mu \mathrm{g} / \mathrm{g}$ in a one-hour measurement with the present apparatus. Installation of a Compton suppression system will improve the measurement substantially in these matrices.

Numerous specimens of pure and substituted $C_{60}$ fullerenes, typically weighing 500 $\mathrm{mg}$, have been analyzed for hydrogen (and simultaneously for other elements such as $C, S$, $\mathrm{K}$, and $\mathrm{Rb}$ ) in support of neutron scattering ${ }^{15}$ and chemical experiments. Early samples of $\mathrm{C}_{60}$ were found to contain large amounts of contaminant hydrocarbon, so high $(0.9 \mathrm{wt} \% \mathrm{H})$ as to vitiate the neutron scattering measurements that were planned; repurification gave a satisfactory product with about $600 \mu \mathrm{g} / \mathrm{g}$. Some of the PGAA measurements were performed with the sample sealed inside the aluminum can intended for the scattering 
spectrometer. In these cases, since the sample was both invisible and nearly as large as the 2$\mathrm{cm}$ beam diameter, the measurements were most accurately reported as a ratio of $\mathrm{H}$ to $\mathrm{C}$. With substituted fullerenes, we were often able to measure other elements, for example the $\mathrm{H} / \mathrm{S}$ molar ratio in a 160-mg sample of $\mathrm{C}_{60}\left(\mathrm{SO}_{4} \mathrm{H}_{8}\right.$ was found to be $1.0 \pm 0.1$ as expected. We have determined both the major alkali and impurity hydrogen in superconducting $\mathrm{K}_{3} \mathrm{C}_{60}$ and its $K_{6}$ and $\mathrm{Rb}_{\mathrm{n}}$ analogs. In one sample we found $0.9 \pm 0.2$ moles $\mathrm{H}$ per mole $\mathrm{Rb}$, suggesting that the sample may have been exposed to moisture after its synthesis.

Another recent application was an attempt to measure the degree of deuteration of a 70-mg sample of a hydrocarbon which was believed to have a $\mathrm{D} / \mathrm{H}$ molar ratio of about 1 . This measurement was not successful with cold neutrons because of neutron scattering in the sample. This effect has been shown theoretically ${ }^{16}$ and experimentally ${ }^{17}$ to lead to analytical errors of as much as tens of percent, depending on the size, shape, and scattering power of the sample, and disappears for nonabsorbing spherical samples ${ }^{18,19}$. Because cold neutrons have a threefold higher cross section for both scattering and absorption compared with thermal neutrons, this source of systematic error is important for smaller samples and lower matrix hydrogen concentration for cold neutrons. The measurement was concluded satisfactorily by measuring a 34-mg sample in the Maryland-NIST thermal PGAA system 4 , matched to a standard with similar ${ }^{1} \mathrm{H}$ content and shape. The $\mathrm{D} / \mathrm{H}$ ratio found was $0.90 \pm$ 0.01 , in agreement with a value of 0.9 determined by other means.

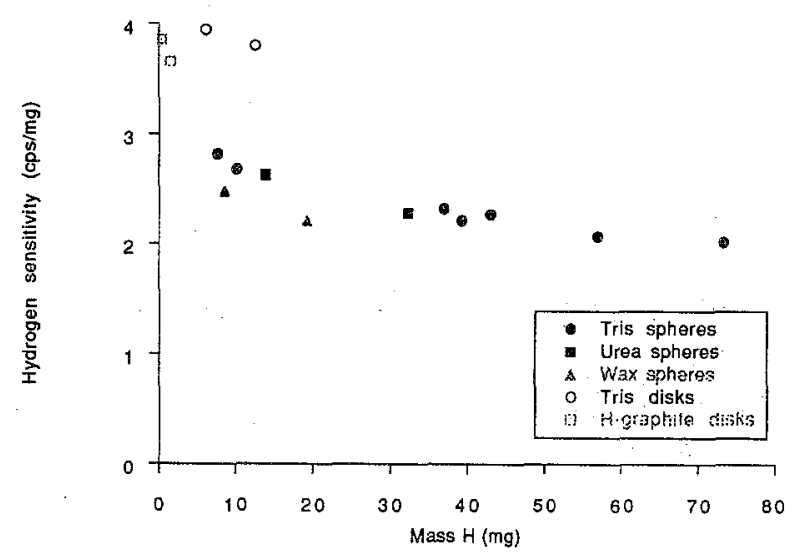

Figure 1: Influence of Scattering on Hydrogen Sensitivity

The scattering of cold neutrons within an analytical sample was tested by irradiating a series of hydrogenous spheres and thin disks prepared by E. A. Mackey ${ }^{19}$. The results are shown in Figure 1. As with thermal neutrons, spherical samples minimize the analytical effects of scattering. A comparison of the experimental results with Monte Carlo calculations for purely elastic scattering with absorption ${ }^{18}$ shows the same trend of decreasing sensitivity with increasing size of sphere, but the numerical calculations for trishydroxmethylaminomethane predict a smaller effect than actually observed. The influence of cold-neutron scattering on analytical accuracy is a rich field for future work. 


\section{Discussion}

In agreement with expectations, the use of cold neutrons in the PGAA system has made quantitative measurement of below $10 \mu \mathrm{g}$ of hydrogen routine in suitable matrices. Improvement to the analytical system is ongoing. Permanent shielding and gamma collimation now being designed will substantialy reduce the background due to the adjacent guide, and a bismuth germanate Compton suppression system being installed should improve the measurability of the single $\mathrm{H}$ line in the presence of cascade gamma rays and continuum, as observed in titanium and iron. The sensitivity (counting rate per gram) is expected to improve when a new liquid-hydrogen cold source is installed:

We thank N. Balsara, C. M. Beck, J. N. Cox, J. R. D. Copley and coworkers, R. G. Downing, E. A. Mackey, and S. F. Treviño for supplying samples.

\section{References}

1. D. A. MEYN, Metall. Trans., 5 (1974) 2405.

2. J. CHEVALLIER, M. AUCOUTURIER, Ann. Rev. Mater. Sci., 18 (1988) 219.

3. M. P. FAILEY, D. L. ANDERSON, W. H. ZOLLER, G. E. GORDON, R. M. LINDSTROM, Anal. Chem., 51. (1979) 2209.

4. D. L. ANDERSON, M. P. FAILEY, W. H. ZOLLER, W. B. WALTERS, G. E. GORDON, R. M. LINDSTROM, J. Radioanal. Chem., 63 (1981) 97.

5. D. L. ANDERSON, G. E. GORDON, E. A. LEPEL, Canad. J. Chem., 61 (1983) 724.

6. D. L. ANDERSON, Y. SUN, M. P. FAILEY, W. H. ZOLLER, Geostand. Newslett, 9 (1985) 219.

7. T. KOBAYASHI, K. KANDA, Nucl. Instr. Methods, 204 (1983) 525.

8. R. M. LINDSTROM, R. ZEISLER, M. ROSSBACH, J. Radioanal. Nucl. Chem., 112 (1987) 321.

9. C. YONEZAWA, M. HOSHI, Y. ITO, E. TACHIKAWA, Proc. 3rd Asian Sympos. Research Reactors, Hitachi, Japan, 1991 (in press).

10. R. M. LINDSTROM, R. ZEISLER, D. H. VINCENT, R. GREENBERG, C. A. STONE, D. L. ANDERSON, D. D. CLARK, E. A. MACKEY, Proc. 8th Intern. Conf. Modern Trends in Activation Analysis, Vienna, 1991 (in press). 11. R. L. PAUL, R. M. LINDSTROM, D. H. VINCENT, this Proceedings.

12. H. J. PRASK, J. M. ROWE, J. J. RUSH, I. G. SCHRÖDER, J. Res. Natl. Inst. Stds. Technol, 1992 (in press).

13. J. E. NELSON, Electrodag 154, Acheson Colloids, Port Huron, Michigan, Argonne Natl. Lab., pers. comm., 1989.

14. C. A. STONE, R. ZEISLER, D. H. BLACKBURN, D. A. KAUFMANN, D. C. CRANMER, in: NIST Tech. Note 1285, C. O'CONNOR (Ed.), 1990, U. S. Govt. Print. Off.: Washington, 1990, p. 116.

15. D. A. NEUMANN, J. R. COPLEY, R. L. CAPPELLETT, W. A. KAMTAKAHARA, R. M. LINDSTROM, K. M. CREEGAN, D. M. COX, W. J. ROMANOW, N. COUSTEI, J. P. MCCAULEY Jr., N. C. MALISZEWSKYJ, J. E. FISCHER, A. B. SMITH III, Phys. Rev. Lett., 67 (1991) 3808.

16. J. R. D. COPLEY, C. A. STONE, Nucl. Instr. Methods, A281 (1989) 593.

17. E. A. MACKEY, G. E. GORDON, R. M. LINDSTROM, D. L. ANDERSON, Anal. Chem., 63 (1991) 288.

18. J. R. D. COPLEY. Nucl. Instr. Methods, A307 (1991) 389.

19. E. A. MACKEY, G. E. GORDON, R. M. LINDSTROM, D. L. ANDERSON, Anal. Chem., (in press). 